\title{
ATHLETIC IDENTITY AND SELF-ESTEEM OF WHEELCHAIR BASKETBALL PLAYERS
}

\author{
Kęstutis Skučas \\ Lithuanian Sports University, Kaunas, Lithuania
}

\begin{abstract}
Background. Disabled persons do not consider and use a single identity to represent themselves. Athletic identity as a wheelchair basketball player can help the process of acceptance and support psychological adjustment. Thus, there is a need to research the association between and the influence of the wheelchair basketball player's qualification and a strong athletic identity on a person's self-esteem (Hawkins, Coffee, \& Soundy, 2014; Martin, Adams-Mushett, \& Smith, 1995).

Methods. The multidimensional Athletic Identity Measurement Scale (Brewer \& Cornelius, 2002) was used to assess self-identity, social identity, exclusivity and negative affectivity of 36 wheelchair basketball players. Selfesteem was evaluated by the adapted V. Stolin's (Столин, 1983) test including nine self-evaluation scales: internal integrity, self-confidence, self-direction, self-image, self-interest, self-content, self-orientation, self-contradiction and self-accusation.

Results. It was found out that the athletic identity value of the players participating in international level competitions (30 points) is statistically significantly higher compared to that of participating in national level events (18 points, $p<.05)$.

Conclusions. Disabled persons of the competition group with better athletic identity represented stronger selfintegrity and were less self-accusative, more self-content, their self-confidence grew and they had a better self-image in comparison with the national level group.
\end{abstract}

Keywords: self-confidence, self-image, persons with physical disability.

\section{INTRODUCTION}

$\mathrm{L}$ ittle is known about the psychological characteristics and preparation of wheelchair basketball players with disabilities (Stephan \& Brewer, 2007; Sherrill \& Williams, 1996; Stryker $\&$ Burke, 2000). Many reasons have been offered as to why athletes with disabilities have been underrepresented in sport psychology research (Sherrill, 1998; Tasiemski, Kennedy, Gardner, \& Blaikley, 2004; Wu \& Williams, 2001). A common theme throughout these writings suggests that a lot of individuals do not consider athletes with disabilities as legitimate or real athletes. Lack of awareness and indifferent as well as negative attitudes towards sport opportunities for disabled people have limited not only the number of research but also funding and recruitment of coaches, sports psychologists, and athletes (Martin et al., 1995; Nasco \& Webb, 2006; Miller, 2009; Hawkins et al., 2014).

Past research works have not been able to demonstrate how athletic identity is associated with characteristics of self-esteem. Disabled persons do not consider and use a single identity to represent themselves. The reason for this is that disabled persons often experience the paradox of chronic illness. The paradox suggests that individuals are simultaneously impelled to accept and defy the limitations of their disability. Moreover, the understanding of which limitations disabled individuals can accept or defy is likely to vary, change and evolve (Hawkins et al., 2014; Martin et al., 1995). One consistency in this experience 
can be the sport group which individuals associate themselves with, their athletic identity as a wheelchair basketball player can help the process of acceptance and act as a factor supporting and facilitating the adjustment. Thus, there is a need for research to consider the association between and influence of wheelchair basketball player's qualification and a strong athletic identity on a person's self-esteem.

The aim of the research was to determine athletic identity and self-esteem of wheelchair basketball players and to evaluate influence of athletic identity on wheelchair basketball players' self-esteem according to the level of participation in wheelchair basketball.

The object of the research was athletic identity and self-esteem of wheelchair basketball players.

Hypothesis: athletic identity can positively influence wheelchair basketball players' selfesteem.

\section{METHODS}

The Athletic Identity Assessment Scale (Brewer \& Cornelius, 2002) was used in the research. The scale is a seven-item questionnaire assessing the person's feelings of self-attribution to the athlete's role. The athletic identity grading scale is divided into three sub-categories: social identity (the depth of the athlete's perception of the role), differentiation (the athlete's perception of the role compared with other roles, such as a friend's role, a family member's role, etc.), and negative effects (negative emotional response rates due to inability to practise and participate in sports competitions). The answers to the questions scored from one (answer "strongly disagree") to seven ("strongly agree"). The scores of individual subscales were summed, and the total score of each individual athletic identity score was derived.

Self-esteem - one of the most important indicators of psychosocial health of disabled persons - was evaluated by the adapted Stolin's (Столин, 1983) test including nine self-evaluation scales: internal integrity, self-confidence, selfdirection, self-image, self-interest, self-content, self-orientation, self-contradiction and selfaccusation. The result points of each scale refer to a certain evaluation: $1-3$ points refer to a low scale evaluation, $4-7$ points - average evaluation, $8-10$ points - high evaluation.

From 2011 till 2012 the research included 36 disabled persons from all over Lithuania (34 males and 2 females). The participants were selected using the improbability sampling strategy. The group included persons after spinal cord injury, cerebral palsy and amputations. The age of the subjects ranged from 18 to 45 years. According to the level of participation in sport two groups of respondents were formed: persons participating in national level competitive sport - involved in sport activities 2-3 times per week and participating in competition in Lithuania several times per year (20 subjects), and persons participating in international competitive sport - regularly involved in sport activities 6-8 times per week and participating in international competitions (16 subjects).

The research results were processed applying the software program SPSS 12.0. The arithmetic mean $(\overline{\mathrm{X}})$ and the standard deviations $(\mathrm{S})$ were calculated. Data statistical differences between subjects were assessed using Student's $(t)$ test. Data was considered statistically significant at the significance level of $p<.05$.

\section{RESULTS}

Only a small number of players participating in national level competitive sports identify themselves as athletes. Only $9.3 \%$ of athletic identity scores equal to 28 points. Research revealed that athletic identity depends on sports qualification. The players participating in international competitions reported moderate to ( 26 points) strong (30 points) athletic identities.

It was found out that athletic identity value of the players participating in international competitions (30 points) was statistically significantly higher compared to that of the players participating in the national level competitive sports (18 points, $p<.05$ ).

Most self-esteem indicators - self-confidence, self-image, and self-content - of wheelchair basketball players participating at the international competition level were better if compared to those from the group participating in the national level. Wheelchair basketball players participating at the international competition level represented stronger self-integrity and were less self-accusative, more self-content, their self-confidence grew and they had a better self-image (Table).

\section{DISCUSSION}

The research has proved that the athletic identity disabled persons depends on the level of their involvement in sports activities. Wheelchair 
Table. Self-esteem of wheelchair basketball players

Note. $*$ - statistically significant difference $(p<.05)$ among the participants with different athletic identity.

\begin{tabular}{|l|c|c|}
\hline \multicolumn{1}{|c|}{ Self-esteem indicators } & $\begin{array}{c}\text { Mean values } \\
\text { of lower athletic identity } \\
\text { group (points) }\end{array}$ & $\begin{array}{c}\text { Mean values } \\
\text { of higher athletic identity group } \\
\text { (points) }\end{array}$ \\
\hline Internal integrity & $5.4 \pm 0.64$ & $5.3 \pm 0.11$ \\
\hline Self-confidence & $7.8 \pm 0.12$ & $8.7^{*} \pm 0.2$ \\
\hline Self-direction & $6.7 \pm 0.23$ & $7.0 \pm 0.41$ \\
\hline Self-image & $7.9 \pm 0.14$ & $8.5^{*} \pm 0.09$ \\
\hline Self-interest & $8.1 \pm 0.15$ & $8.3 \pm 0.24$ \\
\hline Self-content & $7.6 \pm 0.08$ & $8.4^{*} \pm 0.03$ \\
\hline Self-orientation & $5.6 \pm 0.26$ & $5.7 \pm 0.15$ \\
\hline Self-contradiction & $3.8 \pm 0.38$ & $3.7 \pm 0.24$ \\
\hline Self-accusation & $4.7 \pm 0.72$ & $4.1 \pm 0.84$ \\
\hline
\end{tabular}

basketball players participating in international competitive sports showed moderate and strong athletic identities.

The comparison of the research data with the data of similar research works on athletic identity values reveals the fact that athletic identity of wheelchair basketball players participating in international competitions is similar to that of disabled swimmers (Martin, Adams-Mushett, \& Smith, 1995) and lower than athletic identity of ablebodied athletes (Brewer \& Cornelius, 2002) from Great Britain. The results show that athletic identity of wheelchair basketball players in comparison to that of able-bodied persons is highly affected by injury, social limitations caused by the disability and absence of status of the disabled athlete.

The present study revealed the fact that the relationship of self-identity to competitiveness suggests that athletes with strong athletic identities also had good self-esteem indicators leading to a strong desire to achieve success and satisfaction in athletics. This finding supports similar research by Tasiemski et al. (2004).

The self-esteem test showed that the disabled persons identifying themselves as athletes gained more self-confidence, represented a stronger self-integrity and were less self-accusative, also accepted their physical disability easier. Such changes may have been caused by a different environment in which the disabled person identifies himself/herself with persons similar to $\mathrm{him} /$ her easier, also by the example set by other disabled athletes. The interpretation confirms the opinion of other researchers that the socialization process is more successful in a homogenous group which is isolated from the wider society (Skucas, 2012). In such environment values are fostered or changed to different ones quicker. Such results may have been caused by successful internalization process, achieving personal and team goals and the desire to attain those goals. Disabled persons with strong athletic identity had a possibility to identify themselves as active society members acquiring more relevant knowledge and skills, getting physically and spiritually stronger. This finding supports similar research by Martin (2008).

The results of the study support the importance that sport holds athletes with disabilities and provides information that should help increase awareness and acceptance of athletes with disabilities. The results of the current study suggest that coaches and support staff of athletes with disabilities should be aware that their athletes may be highly invested in their sport. Expressing low performance expectations or patronizing attitudes toward performance potential can be psychologically and athletically harmful (Stryker \& Burke, 2000). Coaches should acknowledge these athletes and continue to provide them with challenging, competitive opportunities for athletic excellence.

\section{CONCLUSIONS}

1. Athletic identity of wheelchair basketball players participating in national and competition sport level was different:

- only a small number of the players participating in national level competitive sport identified themselves as athletes.

- the players participating in the international competition level reported moderate to strong athletic identities.

2. Disabled persons of international competition level group with a higher athletic identity showed stronger self-integrity and were less self-accusative, more self-content, their selfconfidence grew and they had a better self-image in comparison with the national level group. 


\section{REFERENCES}

Brewer, B. W., \& Cornelius, A. E. (2002). Norms and factorial invariance of the Athletic Identity Measurement Scale. Academic Athletic Journal, 15, 103-113.

Hawkins, C., Coffee, P., \& Soundy A. (2014). Considering how athletic identity assists adjustment to spinal cord injury: A qualitative study, Physiotherapy, 100(3), 268-274.

Martin, J. J., Adams-Mushett, C., \& Smith, K. L. (1995). Athletic identity and sport orientation of adolescent swimmers with disabilities. Adapted Physical Activity Quarterly, 12, 113-123.

Martin, J. J. (2008). Multidimensional self-efficacy and affect in wheelchair basketball players. Adapted Physical Activity Quarterly, 25(4), 275-288.

Miller, K. E. (2009). Sport-related identities and the toxic jock. Journal of Sport Behaviour, 32, 69-91.

Nasco, S. A., \& Webb, W. M. (2006). Towards an expanded measure of athletic identity: The inclusion of public and private dimensions. Journal of Sport and Exercise Psychology, 28, 434-453.

Sherrill, C. (1998). Adapted physical activity, recreation and sport: Crossdisciplinary and lifespan (5th ed.). Boston, MA: WCB Mc Crawl-Hill.
Sherrill, C., \& Williams, T. (1996). Disability and sport: Psychosocial perspectives on inclusion, integration and participation. Sport Science Review, 5, 42-64.

Skucas, K. (2012). Resocialization of persons with spinal cord injury from the in aspects of self-esteem and biosocial skills. Special Education, 2(27), 179-185.

Stephan, Y., \& Brewer, B. W. (2007). Perceived determinants of identification with the athlete role among elite competitors. Journal of Applied Sport Psychology, 19, 67-79.

Stryker, S., \& Burke, P. J. (2000). The past, present, and future of an identity theory. Social Psychology Quarterly, 63, 284-297.

Tasiemski, T., Kennedy, P., Gardner, B. P., \& Blaikley, R. A. (2004). Athletic identity and sport participation in people with spinal cord injury. Adapted Physical Activity Quarterly, 21, 364-378.

Wu, S. K., \& Williams, T. (2001). Factors influencing sport participation among athletes with spinal cord injury. Medicine and Science in Sports and Exercise, 33(2), 177-181.

Столин, В. Б. (1983). Самосознание личности. Москва. 